\title{
Innovation and Evaluation in the Brazilian Higher Education Culture: Interdisciplinary and General Education
}

\author{
Elisabete M. A. Pereira' ${ }^{1}$, Ana Maria Carneiro², Mirian Lucia Gonçalves ${ }^{3}$ \\ ${ }^{1}$ Faculty of Education, University of Campinas, Campinas, Brazil \\ ${ }^{2}$ Center for Studies in Public Policy, University of Campinas, Campinas, Brazil \\ ${ }^{3}$ Virtual University of São Paulo, São Paulo, Brazil \\ Email: eaguiar@unicamp.br, anamaria.carneiro@gmail.com, mirian.unicamp@gmail.com
}

Received 13 August 2014; revised 10 September 2014; accepted 18 September 2014

Copyright (C) 2014 by authors and Scientific Research Publishing Inc.

This work is licensed under the Creative Commons Attribution International License (CC BY). http://creativecommons.org/licenses/by/4.0/

cC) (i) Open Access

\begin{abstract}
The aim of this study was to present partial results of the Interdisciplinary Higher Education Program (ProFIS) related to the interdisciplinary general education proposal, which represents an innovation in the Brazilian Higher Education culture. The general education provided by the program is concerned in preparing students with greater knowledge, critical sense by expanding their knowledge and culture, and makes them critical citizens and professionals. Besides curricular innovation, the course aims to establish a policy of affirmative action through the inclusion of public school students. Briefly, it presents the general education as curriculum emphasis adopted by universities in various parts of the world. Then, it presents the ProFIS proposal, its current development stage and the analysis of partial results of the evaluation process under development. The evaluation process is developed with teachers, students and course coordination.
\end{abstract}

\section{Keywords}

General Education, Higher Education, Evaluation, Curriculum Innovation, University Culture

\section{Introduction}

Since 2011, University of Campinas (Unicamp ${ }^{1}$ ) has developed a course that with innovations throughout its structure develops a new way of designing teaching in higher education and meets the Brazilian educational

\footnotetext{
${ }^{1}$ Unicamp is located in Campinas, a one million people city, near from São Paulo. Unicamp is public state university, with less than 50 years It has a very important place in the scenario of research, teaching and innovation in Brazil as a research university. Unicamp accounts for 10 of academic research in Brazil, in terms of papers (more than 3 thousand) and master and doctorates degrees (more than 2500) each year.
} 
policy of social inclusion. This is the Interdisciplinary Higher Education Program—ProFIS, a course which presents innovations in various aspects: the first is the composition of its faculty, which comes from all areas and academic units of Unicamp; it is taught in full-time; its curriculum composition is interdisciplinary and its structure is aimed to include the student in general education activities focused on scientific, social, human, cultural, economic, political and ethical issues. The student body is composed entirely of former public high school students, its selection process uses the scores obtained in the National High School Exam (ENEM) ${ }^{2}$ and its duration is two years. The course planning was made by a Multidisciplinary Commission and its project was discussed in all units of Unicamp. Thus, the course was greatly accepted by the academic community and public recognition as showed by the award obtained in April 2013 from the Péter Murányi Foundation as the exemplary education experience to improve life quality of people located under the $20^{\circ}$ North parallel.

Still among the innovations that make the ProFIS an innovative program is the organization of a process of continuous evaluation with longitudinal studies coordinated by the Center for Public Policy Studies (NEPP/Unicamp). The process is unprecedented in assessing courses in Brazil by going beyond a simple verification of satisfaction of teachers and students. It is a systematic activity that begins in student enrollment, follow-up during the course and insertion in the labor market. The evaluation methodology includes the monitoring of students through data on their performance, performance of teachers, interviews and periodic questionnaires with teachers and students.

The program responds to a social inclusion policy effectively guaranteeing the permanence of students by meeting the students' economic needs and learning difficulties. The effective social inclusion policy allows the access of a clientele quite similar to that with potential for higher education in socioeconomic terms, selecting them by a system that ensures the geographical representation of public schools. About 120 vacancies are annually offered to students best ranked in the ENEM from each of the 96 public schools in Campinas, with a limit of two students from each school.

The impact in terms of representation of public schools was immediate when the first class was selected (2011). Up to the offering of this course, more than half of these schools had no student enrolled at Unicamp. Part of these the students could not be approved in the selection process and part of them due to the phenomenon of self-exclusion, students do not even think about studying at Unicamp. This inclusion policy resulted in the inclusion of students who are the first generation to attend higher education (around 80\%).

Still as effective social inclusion policy, all students receive a scholarship and food and transport assistance, as well as psychological support, medical care, dental and legal support, which are offered to all students at Unicamp.

The development of a continuous evaluation system is part of the course planning and has been implemented since its beginning to follow the three first classes since their university entry, during the course, professional insertion and after this. The evaluation process seeks to collect data from all actors involved in the course: coordination, faculty, students and graduates, since it is planned to be developed during 10 years. The process provides ProFIS data on the adequacy of its objectives, curriculum design, pedagogical work of teachers, student learning, impact on their lives and on the inclusion policy of the program. It searches to compare data from various sources, resulting in potent clarifications to reaffirm and strengthen the goals and practices employed or revise and reconstruct trajectories, goals and policies (Macdonald, 1982).

The evaluation systematic is based on the understanding that assessing is a process that takes place in a complex and plural context, aiming that its design gives visibility to the variables that compose it.

The participative nature of the evaluation recognizes the existence of a pluralism of values held by the different agents (coordinators, teachers, students and other stakeholders) and plays the role of intermediary in the dialogue between these different agents, framed by an educational, social, political, psychological and cultural character. The university culture in general, although already performing evaluations, has not yet established an evaluation culture of great comprehensiveness. The evaluation implemented in the ProFIS represents a new moment to transform this culture.

This paper presents partial results of the ProFIS evaluation with data from students and teachers that relate to the proposal of interdisciplinary general education and training. We will present data on the evaluation of the scope of general and interdisciplinary education. We seek to answer, even if it is still preliminary, the first hypothesis of the evaluation system, established based on the major goal of the course, which is that the interdisci-

\footnotetext{
${ }^{2}$ This program does not use the usual selection system to universities called "vestibular".
} 
plinary general education of ProFIS expands the knowledge and general culture of the student with investigative attitude, critical view and civic engagement.

Besides the introduction, the article is composed of three more sections. The first section presents and discusses the evolution of general education as emphasis on university education worldwide. The second section presents the ProFIS design and the third discusses the results obtained by means of continuous evaluation related to general and interdisciplinary education offered in the first two years of the program (2011 and 2012). Finally, we draw concluding remarks critically addressing the results and challenges of this type of higher education.

\section{General Education and Interdisciplinary Education}

The theme of general and multidisciplinary education is of great importance in the present higher education scenario. Although since the formulation of modern university, there is an ongoing debate about the role and function of the university: promote broad and cultural education or specific and technical training; forming citizen-professional ${ }^{3}$ or expertise professional; train for the labor world or for the labor market.

The concern with general education is not new. It has been a constant concern in the process of student education of the university institution from its beginnings until the present day. Especially in contemporary world, it has been considered one of the most valuable contributions that the university can do for the good of the student and for society in general, and is essential for a society that wants to be free, fair and democratic. The understanding of the need for a more comprehensive education has been debated more intensely in present days and has been more considered in the structuring of universities both in the Western and Eastern world.

According to Peterson (2012), universities around the world have sought the most diverse forms and compositions to provide students with a general education. The author shows that developed or developing countries are revitalizing the general education somehow. In his book "A global framework: Liberal Education in the Undergraduate Curriculum” presents experiences in Hong Kong, Singapore, Australia, Sweden, Japan, Russia, Bangladesh, Poland, South Africa, Turkey and in Central European countries.

Although the diverse understanding of the importance of general education, its purpose and aims are the same, i.e., educating an individual with broad knowledge of the interrelationships of knowledge and of this with human, cultural and natural issues. The curriculum composition is specific to each country and each institution.

According to Nussbaum (1997), general education refers to Socrates, who said that to be meaningful, life must be guided by an internal examination and that it is proper to individuals that go beyond the narrow terrain of professionalism, the analysis of his actions. Aristotle (2005: p. 34) reported that for Aristotle, general education means "a susceptible provision of creation accompanied by true reason and the ability to produce with correct reasoning”.

In general, we can highlight four main approaches to structuring general education curriculum (Newton, 2000). They are: 1) focused on Great Books, 2) focused on academic disciplines, 3) focused on educating citizen and 4) focused on Interdisciplinary approach. Each approach brings its understanding of what one should do to train the student as an educated man and how to develop the curriculum to achieve it.

Approach focused on Great Books is dedicated to intellectual formation and is convinced that through the knowledge of ideas contained in the classical books of all areas, the student acquires a broad knowledge of culture. This approach understands that man must have in his possession own ideas from the knowledge of cultural heritage. According to this approach, literature classics examine fundamental and perennial issues about the universe, man and society in an integrated manner and promote the understanding of how the issues of world history are presented today. For this, the analysis, study, discussion of major philosophical, scientific, literary and artistic works, which have became classics, develop intellectual skills and prepare students for the challenges of today's world. This approach is now used by several American colleges and universities such as: University of Dallas (Texas), University of Notre Dame (Indiana); Kansas State University; Saint John's College (Annapolis, Maryland); Gutenberg College (Oregon); St Mary's College and Thomas Aquino College (California), North Park College and Shimer College (Chicago, Illinois).

Approach focused on academic disciplines seeks to ensure organicity and coherence to general education program and opposes the elective system curriculum. Typically, this approach asks students to develop courses in various areas such as physical sciences, literature, art, social sciences, humanities, life sciences, natural sciences. In each, the perspective is the knowledge of basic concepts and the method of work and research in the area.

\footnotetext{
${ }^{3}$ We use the term citizen-professional as proposed by Pereira (2010).
} 
Courses are developed by experts and independently planned and executed. It is not an interdisciplinary approach and the degree of cooperation between teachers is small. This approach is widely used in colleges and universities worldwide, less due to its scope and more due to the tradition of fragmentation between areas of knowledge.

The third approach, focused on educating citizen, considers one of the basic functions of university education which is the formation of critical and participatory citizen in a democratic society. It is based on the belief that education should foster civic engagement to explore the potential of citizens of its students. The curriculum is focused on social, moral and civic problems and prepares young people to act as citizens of an egalitarian, democratic and fair society. The curriculum is developed around real problems which must be addressed, studied and reflected in the complexity of issues and on the understanding and integration of factors. Courses aim to promote knowledge, values and civic experiences to educate proactive people, engaged in local, national and global society. This complexity requires an approach with contributions of various disciplines and the understanding the transcendence of these limits into a new arrangement of integration.

The fourth approach, the Interdisciplinary approach, is the most current form of general education and is in part or entirely being used by various universities worldwide. It seeks to make the student understand the interrelationship of knowledge and complexity of world issues, which, for their solution, need knowledge that go beyond a single discipline or field. In the United States, higher education includes, as part of the general education requirements, interdisciplinary studies by working with themes rather than disciplines. In some cases, universities or colleges are organized into interdisciplinary units, changing their departmental structure (Davis, 1995). In 2005, the organization of courses of the School of Arts, Sciences and Humanities (EACH) at University of São Paulo (USP), Brazil, did similar approach, i.e., through interdisciplinary curriculum and no departments. The goal of most courses and interdisciplinary programs is to integrate contributions from different academic disciplines or study fields, so that issues, problems and phenomena under study are better understood.

Those who support interdisciplinary education argue that disciplinary approaches for education are reductionist and share knowledge instead of generating comprehensive explanations about the world. They argue that interdisciplinary education seeks holistic understandings of social and natural world (Morin, 1999; Fazenda, 1999; Repko, 2008). When students are encouraged to work problems in an interdisciplinary approach, a series of intellectual skills that include problem solving, reasoned reflection, assessment and redirection, synthesis and integration and critical thinking are developed. It is believed that developing the ability to see and use various perspectives encourages the respect for others' perspectives, willingness and ability to question assumptions about the world and about ourselves, expanding horizons and students' perspectives, the ability to think creatively and innovatively. As a result, those who support interdisciplinary education argue that interdisciplinary study is an excellent preparation for the role of citizen and worker in a plural, technological and democratic society.

Columbia University (USA) today uses an interdisciplinary approach with a curricular structure formed by what they call "Nine ways to know" or nine lenses that create a framework for understanding the world: reason and value, social analysis, compared cultures, language, laboratory of sciences, quantitative and deductive reasoning, historical studies, literature, visual and performing arts. Harvard University organized the new curriculum for general education from 2007 through integrated courses, with integrated planning of teachers from various areas, breaking with the disciplinary perspective. Integrated planning intends to define the most important concepts and attitudes that students should acquire about each area of knowledge. These courses can be developed by different teachers in an integrated perspective or by teachers who have a broad perspective of the knowledge to be taught (Pereira, 2010). The University of Stanford presented its interdisciplinary program and informed that these courses go beyond the boundaries between departments and disciplines.

In Brazil, there are already a large number of public universities that have curriculum focused on general education and interdisciplinary approach, particularly 18 federal universities with programs called Interdisciplinary Bachelor degree. Unicamp has eight undergraduate courses with emphasis on general education and interdisciplinary structure, in addition to ProFIS, which is different type of course. Each program follows its own way to provide general education. This freedom and autonomy in curriculum structuring are typical of this approach. What unites and identifies the emphasis is the purpose, the goal.

In the six courses offered by the Faculty of Applied Sciences, located at the campus of Limeira/SP (Sports Science, Nutrition, Manufacturing Engineering, Production Engineering, Public Administration and Administration), students complete disciplines of the general basic common core, which is composed of knowledge on humanities and applied social sciences. 
ProFIS, course analyzed in this study, aims to develop general and interdisciplinary education. To monitor and evaluate the innovations of ProFIS, the Center for Public Policy Studies (NEPP/Unicamp) established a continuous evaluation process. NEPP uses participatory methodology involving different actors in the process of defining what should be assessed, collected and analyzed. According to Zackiewicz (2005), participatory evaluation does not just mean the involvement of many people, but especially the negotiation from different perspectives, values and interests often conflicting, resulting in the involvement of various interpretations on the phenomenon under study, allowing evaluating it in all its complexity.

Participatory evaluation involves the use of a combination of quantitative and qualitative methods (Bach, 2010). This is operationalized through a multidisciplinary team, through an Evaluation and Advising Committee that interacts with the research team on a regular basis and by conducting validation panels with stakeholders and specialists.

Besides being participative, evaluation has a quasi-experimental design that seeks to compare the results of some variables of beneficiaries with comparison groups that have a similar socioeconomic profile. The first group is formed by the candidates who had applied to ProFIS but did not accomplish registration (some were called but decided for other opportunity). From this comparison group, it is possible to analyze the impact of this general education course and the undergraduate course at Unicamp. The second comparison group is formed by other students enrolled at Unicamp, who were admitted by the usual entry exam, called "vestibular". This group was selected using propensity score matching and it has a similar socioeconomic profile as ProFIS students. This group helps to contextualize the impact of general education approach, providing benchmarks.

The proposed evaluation has four objectives: to evaluate the implementation and feasibility of ProFIS as a general and interdisciplinary education program; to evaluate the selection process of ProFIS, to promote social inclusion and, finally, to evaluate the impact of the ProFIS on the student's education and career paths. This paper presents and discusses the preliminary results of the first objective.

The evaluation methodology uses various sources of data such as:

- Two questionnaires answered by students and members of comparison groups (QI-enrollment questionnaire, and QAA — annual follow-up questionnaire);

- A questionnaire answered only by ProFIS students (QM-enrollment questionnaire);

- Interviews with teachers and coordination;

- Secondary data on academic records provided by the Academic Board (DAC) and the Admittance Commission (Comvest);

- Other secondary data on the management of the program provided by the DAC, General Board of Human Resources (DGRH) and Student Support Service (SAE), among others.

To analyze whether the interdisciplinary general education program increased the student's knowledge and general culture with the development of investigative attitude, critical view and civic engagement, data from the QAA 2012 and interviews with teachers who acted in the course in 2011 and in 2012 were used.

The QAA contains questions related to all outcomes and impacts that will be measured over time, considering the trajectories of participants in relation to educational and professional trajectory and social participation. The evaluation process aims to keep all subjects (ProFIS classes and comparison groups) for about 10 years. In each year, subjects respond parts of the questionnaire according to their current situation in relation to higher education and professional work.

\section{General and Interdisciplinary Education at the ProFIS}

The Working Group set up for ProFIS planning was composed of professors from various fields who had the challenge of thinking together a course to go beyond their specific areas.

The objectives are the acquisition of knowledge in humanities, natural sciences and art, seeking integrated approaches on knowledge, on its relations with the world, environment and the world of work and understanding of themselves as individuals and citizens living in a diverse and globalized society constantly changing. To achieve the goals, curricular activities are designed to develop skills in oral and written communication in the mother tongue and foreign language; logical, formal and abstract reasoning; ethical responsibility as to society and environment; critical and analytical thinking about cultural diversity and the complexity of human life in its artistic, scientific, literary, historical and cultural expression. The curriculum consists of 28 mandatory disciplines. In addition, the student must make 8 more credits in elective disciplines in any of the courses at Unicamp. 
At the end of the course (after two years, recommended finishing term, or three years maximum finishing term), students receive the certificate of Interdisciplinary Higher Education and may have access to a place in one of the regular undergraduate courses at Unicamp ${ }^{4}$. We had two graduation (2012 and 2013), and a total of 110 students class completed the course and all graduates entered in undergraduate courses at Unicamp. Almost all of the career choices that students mentioned at the moment of the enrollment have changed during the program and, according to their testimony, the breadth of knowledge provided by the course, the experience in the university, contact and interaction with teachers from various areas were factors that provided greater maturity for more adequate choices.

On the other hand, the course design and the financial subsidies through scholarship assuring permanence allowed exclusive dedication to the course, to their intellectual and cultural development, to the development of a research project through the scientific initiation, explained above, which also favored a more mature choice about their careers.

Another important aspect related with permanence on higher education is the pedagogic support program provided by Ph.D. and Masters students. Public high schools in Brazil do not provide in general a good education and their students come to higher education with learning problems. The pedagogic support program helps professors to ensure the meeting of learning problems specific of each class.

The interdisciplinary aspect of curriculum development, although being one of the key points of the project, is still poorly understood and worked in the Brazilian higher education system and, therefore, has been one of the points that deserves special attention, since for all professors, it is a new approach.

An activity developed as a key point of the ProFIS curriculum is the scientific initiation (SI). It is expected through it that students should able to develop research skills, reflect on real problems from concepts, techniques and scientific methods, and experience contact with research groups, in addition to presenting reports and papers in events. Teachers have reported various difficulties in the work of vocational guidance to ProFIS students; however, most of them believe that the experience with research has much to contribute to students, since it allows the development of autonomy and criticality.

For students, SI contributes to a civic education to achieve the importance of constant learning through investigative thinking, for the expansion of critical thinking and to deepen their knowledge in a particular area. They also report that they learn to develop and aim to improve the quality of life of people, to develop work that is useful for society. They report that the IC as an opportunity to:

"Mature and think about how one should act in professional life and the awakening of curiosity and desire to perform further research" (ProFIS student, class of 2011).

\section{Analysis of Data on Interdisciplinary Education}

This section presents and discusses the data about aspects of interdisciplinary education using interviews with professors and questionnaires. The interviews with professors were conducted at the end of each semester between 2011 and 2012, and some were done twice, since some disciplines were offered more than once. Altogether, 35 interviews were done. Teachers were interviewed about aspects of the course, among them, the character of general and interdisciplinary education, which will be the object of analysis in this text.

We sought to know, in the opinion of the faculty, whether the curriculum is appropriate for the proposed model of interdisciplinary general education. In the interview, professors were asked about the contribution of their discipline for the development of four skills provided in the course's educational project, such as:

1) Oral and written communication in the mother language and foreign language, reading and interpretation of graphical, computational languages and statistical information;

2) Logical, formal and abstract reasoning related to aspects of qualitative and quantitative analysis of realworld phenomena;

3) Critical and analytical thinking on cultural diversity, the organization of the world in its literary, philosophical, sociological, historical, artistic and aesthetic expressions;

4) Understanding of social institutions and environmental and ethical concerns of contemporary society.

The responses regarding the degree of contribution of disciplines were transformed into a scale from 1 to 3 ,

${ }^{4}$ Only few courses do not offer place to ProFIS graduate students. The number of places varies by course, for examples: medicine offers 5 places, pedagogy 4, agricultural engineering 3 and so on, totaling 132 places. 
where 1) is for small contribution, 2) intermediate contribution and 3) great contribution, and also NA-not applicable. The result is shown in the Table 1 . As can be seen, the opinion of teachers is that all the skills were covered to a greater or lesser degree by the disciplines considered. The ability worked with more emphasis was logical reasoning, in part due to increased load of disciplines in the area of exact sciences. It also draws attention that oral and written communication skills were the only worked transversely in all disciplines. The skill less worked was the understanding of social institutions, and four disciplines showed that this ability does not apply to the program developed.

In interviews, when asking the teachers' opinion about the interdisciplinary nature of ProFIS, they mentioned several elements of general education and interdisciplinary approach. The teachers' speeches were worked by the methodology of content analysis, according to Bardin (1991).

The adequacy of the curriculum content to the interdisciplinary nature, the speeches were classified into four categories as shown in the Table 2.

As can be seen, most teachers perceived that the curriculum content is adequate. Some speeches exemplify the teachers' opinion:

"The curriculum content is suitable. Students even ask for extra courses and summer courses in the subject, but teachers do not have schedule availability" (Ethics and Bioethics Teacher).

"They tried to see the scientific text integrated with other disciplines-e.g. Mathematics text written in

Table 1. Interviews performed with teachers of mandatory disciplines in 2011 and 2012.

\begin{tabular}{|c|c|c|c|c|}
\hline Discipline & $\begin{array}{l}\text { Oral and written } \\
\text { communication }\end{array}$ & Logical reasoning & Critical thinking & $\begin{array}{l}\text { Understanding of } \\
\text { social institutions }\end{array}$ \\
\hline Professions & 2 & 2 & 2 & 1 \\
\hline $\begin{array}{l}\text { Physical activity, health promotion } \\
\text { and quality of life }\end{array}$ & 2 & 1 & 2 & 3 \\
\hline Sciences, technology and society & 2 & 2 & 2 & 2 \\
\hline Environmental engineering & 2 & 2 & 2 & 3 \\
\hline Ethics and bioethics & 2 & 1 & 3 & 3 \\
\hline Evolution & 1 & 1 & 2 & 1 \\
\hline Physics & 1 & 3 & 1 & 2 \\
\hline Plane and analytical geometry & 1 & 3 & 1 & 1 \\
\hline Introduction to history & 2 & 2 & 3 & 2 \\
\hline Introduction to statistics & 2 & 3 & 3 & NA \\
\hline Reading and production of texts (I and II) & 3 & 1 & 1 & NA \\
\hline English (I, II, III and IV) & 3 & 2 & 3 & 1 \\
\hline Basic mathematics & 1 & 3 & 1 & NA \\
\hline Human body & 3 & 2 & 1 & 1 \\
\hline Planet earth & 1 & 3 & 3 & 1 \\
\hline First aids & 2 & 1 & NA & NA \\
\hline Chemistry & 2 & 3 & 1 & 1 \\
\hline Information technology & 2 & 2 & 1 & 1 \\
\hline Tecnologia da informação & 2 & 1 & 1 & 1 \\
\hline Fundamental literature texts & 2 & 1 & 1 & 1 \\
\hline
\end{tabular}

Note: Scale of contributions: 1-small contribution; 2-intermediate contribution and 3-great contribution; NA-Not applicable. 
Table 2. Adequacy of the curriculum content to the interdisciplinary nature according to teachers' speech.

\begin{tabular}{ccc}
\hline Classification & $\%$ & $\%$ cumulative \\
\hline Well diversified and good curriculum content & $5.7 \%$ & $5.7 \%$ \\
Adequate curriculum content & $75 \%$ & $80.7 \%$ \\
Tight curriculum content & $2.8 \%$ & 83.5 \\
Not so adequate curriculum content & $14.2 \%$ & $97.7 \%$ \\
Inadequate curriculum content & $2.3 \%$ & $100 \%$ \\
Total & $100 \%$ & \\
\hline
\end{tabular}

Note: Source: Interviews with teachers of mandatory disciplines in 2011 and 2012.

English and then, there was integration with the reading and production teacher” (English Teacher).

"No, the discipline has only 2 credits, which prevents proper implementation of content that could be worked" (Planet Earth Teacher).

For a curriculum with innovations to be properly implemented, the course coordinator should provide the adequate conditions for it. Thus, the interview asked if the teacher had received orientation on interdisciplinary work. The speeches of teachers were classified into: Yes 82.8\%, No 14.2\%, and one of the teachers said that orientation was given in the Institution itself (2.8\%). Some speeches exemplified the view of teachers:

"Yes. This aspect was discussed even among teachers who would take the discipline" (Ethics and Bioethics

Teacher).

"There was a collective space for discussion at the beginning of the semester. Other meetings were held during the first six months" (Geometry Teacher).

Teachers could present their concerns about the program. In general, they perceive it as a good program that should be continued, as seen in the following statements:

"It is a positive program that must be experienced" (Planet Earth Teacher).

"The curriculum content is challenging for the students and was chosen to contribute to their formation. Students who enroll in an undergraduate program will be ahead of those who entered by regular selection process because they will know to do qualitative and quantitative research” (English Teacher).

Teachers were also asked about the positives and negatives aspects of the course. Positive aspects were:

- Interdisciplinarity;

- The entry into the University by a process other than regular selection process;

- Work with a different audience, which brings a new challenge to academic work. Negative aspects were:

- Lack of articulation among teachers, and;

- Lack of greater integration of disciplines.

\section{Students Questionnaires}

The questionnaires were answered by the students from 2011, 2012 classes and by comparison groups. ProFIS students were asked what they considered to be the main contribution of the course. The intention was to see how students understand the ProFIS course. The figure shows the result of 2011 students (86 subjects).

According to Figure 1, the most common contribution of ProFIS is related to Interdisciplinary general education (32\%) and for $28 \%$ of respondents, the greatest contribution is the access to undergraduate courses at Unicamp.

For further understanding about skills developed by ProFIS, the questionnaire asked for a self-evaluation on the current proficiency level in 12 skills (Figure 2). The same question tried to capture the contribution of the course for development of skills. Both parts of the question used a 1 to 5 Likert scale: 1 indicates very low proficiency level and 5 very high proficiency level. The members of the comparison group also answered this question and the comparison of results is presented in Figure 3. 


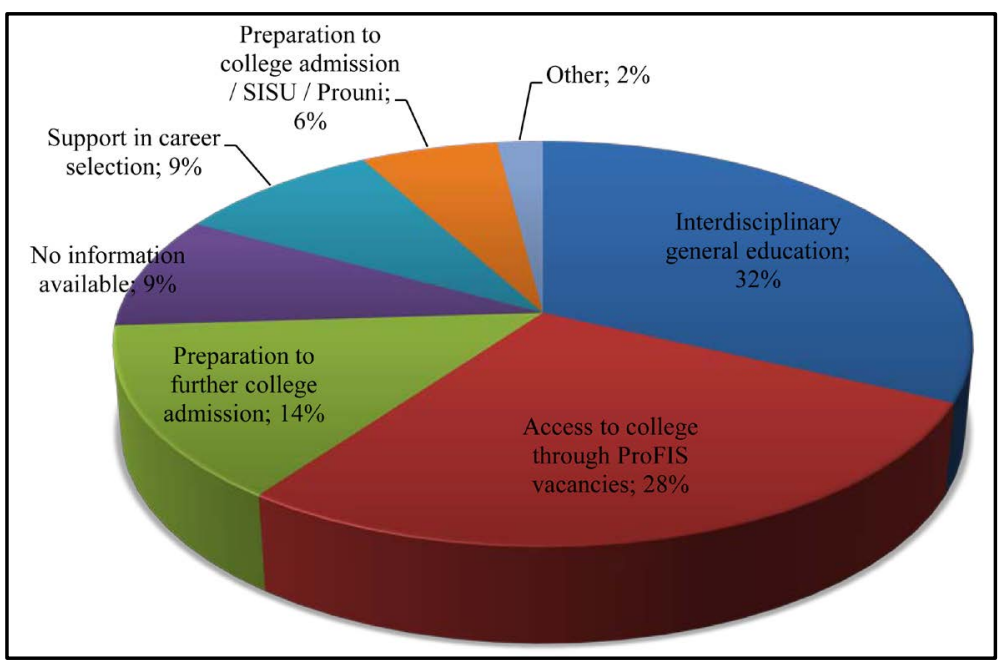

Source: QAA 2012.

Figure 1. Main contribution of ProFIS, class of 2011.

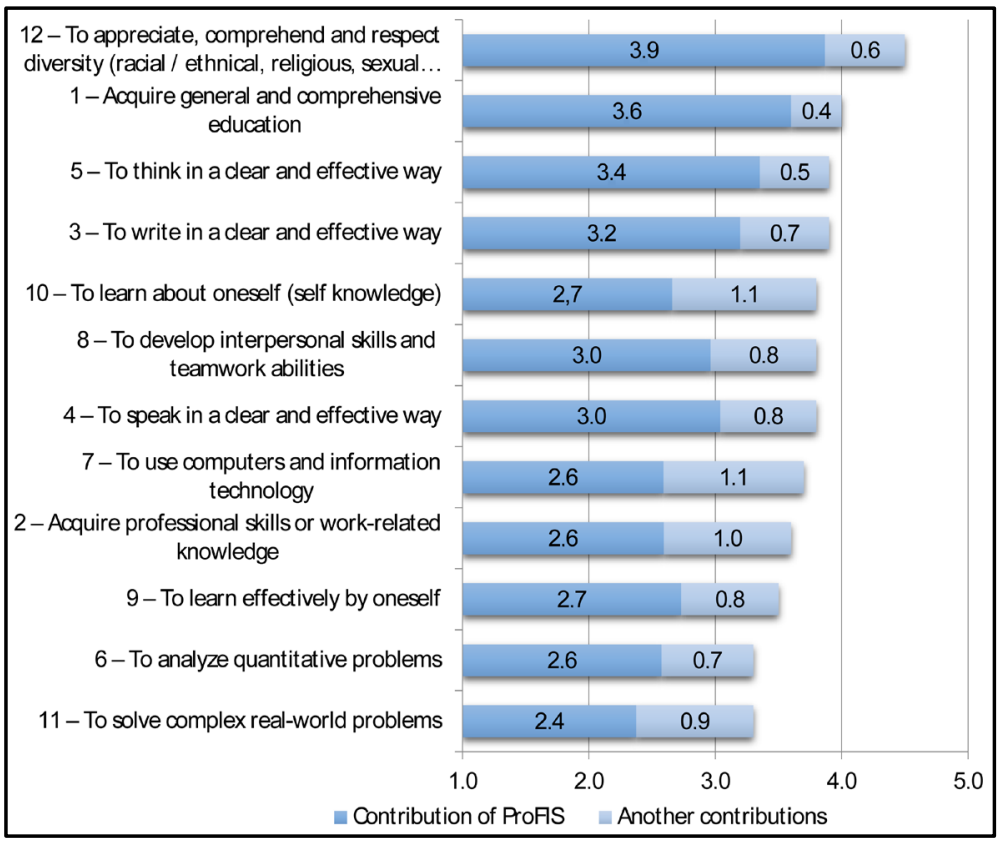

Source: QAA 2012.

Figure 2. Contribution of the course to the current proficiency level by skillsProFIS class of $2011(n=82)$.

The comparison data are presented in Figure 3, shows no differences in the proficiency level of self-evaluation of ProFIS students in relation to their skills when compared to the group admitted through regular college admission process developed by Convest for undergraduate courses.

However, some points should be highlighted. The first refers to the highest average grade in both groups, namely, the ability to appreciate, understand and respect diversity in various aspects. For ProFIS students, the contribution of the course is a little higher. Although this is not the only goal of general education, it is an important goal, in view of the structural change in contemporary world, where multiculturalism is placed in evidence and, according to Favacho and Paz (apud Godoy, 2011), the professional of the XXI Century is expected to be prepared to think and collaborate with the social-historical development of the present and future times, and be better prepared to deal with diversity, including ethnic, religious and sexual issues. 


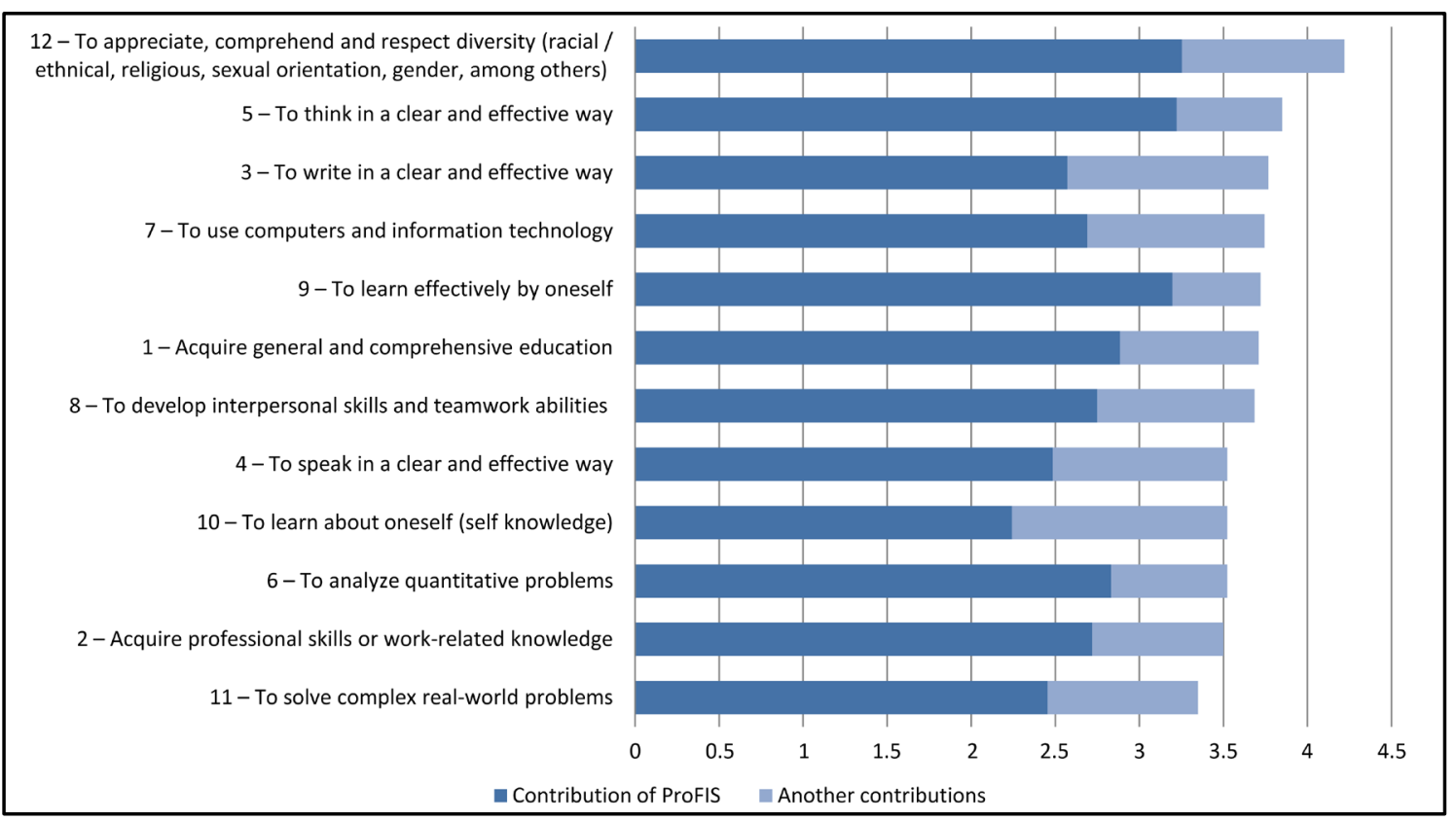

Source: QAA 2012.

Figure 3. Contribution of the course to the current proficiency level by skills-Comparision Group of Vestibular 2011 (in 2012) (after 2 years of undergraduate program) $(n=86)$.

The second is when it is considered only the average value for the specific contribution of courses in each skill. The average values of ProFIS students are higher especially in relation to the first skill (general knowledge), which is one of the program focus. The skills 3, 4 and 10 (speaking, writing and self-knowledge), are also pointed out. In relation to college admission, the largest difference in average grade specific of the course is on skill 9, related to the ability of learning and has autonomy in their studies.

Finally, it was investigated how students relate university education with possible future professional performance. Students were asked if they believe that the course had given them conditions for adequate performance and for meeting the needs of professional practice supported on scientific knowledge, with social vision, based on ethics and human values. Students responded on a scale from 1 to 5 , where 1 means "no condition", and 5 "total condition", and the results are as showed in Figure 4.

In the first category, which states that the course gave adequate conditions for professional activities, it is interesting to note that most ProFIS students reported that the course gave "some condition", which is quite understandable in view that the course does not offer a particular professional qualification, but skills that can be used in any professional position, while the comparison group (CG) reported that their course gave them "much condition".

As for having a professional practice supported on scientific knowledge, ProFIS students and CG both reported that the course has given "much condition" (38.9\% and 47.1\%, respectively). For an activity with social vision, 38.9\% of the ProFIS group considered that the course gave them "much condition" and the same percentage believes that the course gave them "total condition". To Pereira (2002), with a new view of what is to be a professional, the responsibility for student education has changed from the technical vision to learning of values and social, affective and human attitudes.

In relation to the conditions offered in the course for professional practice "based on ethics" and "human values", the ProFIS students are distributed in the same proportion in both. The group focuses primarily on the claim that the course has offered "much condition" ( $40.3 \%$ in both categories), followed by the statement that it gave "some condition" $-36.1 \%$ for action "based on ethics" and 33.3\% for action based on "human values".

The evaluation of students in relation to values that include collective interests allows us stating that the program has strived to ensure that their education activities are turned to the development of citizens who act as responsible professionals, individually and collectively, to build a better society. "The aim is education with human face" (Pereira, 2002: p. 44). 


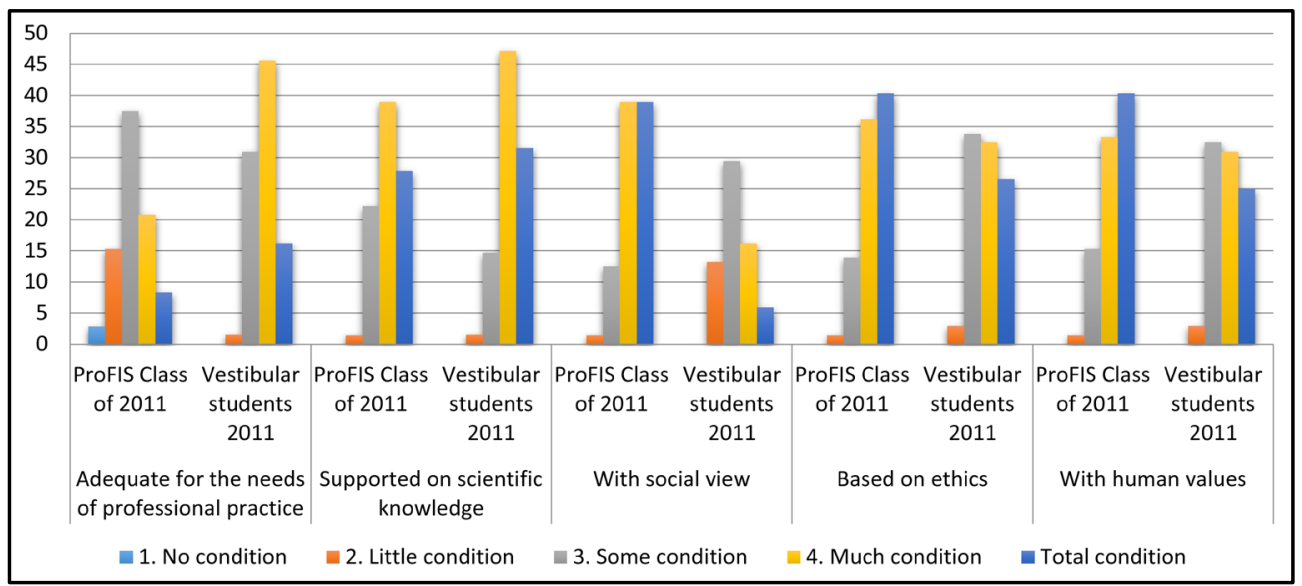

Figure 4. Contributions of the course for professional practice, group of students admitted through regular college admittance process $2011(n=64)$ compared to ProFIS class of $2011(n=65)$. Source: QAA 2012.

\section{Final Conclusions}

The ProFIS features as its main curriculum innovation the fact of being a General Education Program, with disciplines from all areas of knowledge and interdisciplinary proposal. This work presented the partial results of the evaluation program of its curriculum structure.

Specifically regarding to interdisciplinary program, teachers pointed out the "integration with other teachers", "integration with other disciplines", "curriculum content suitable for interdisciplinary program" as aspects favored by curricular structure. According to the coordinator, there is still no $100 \%$ integration, but its action is to provide conditions for integration through meetings with teachers before starting the semester and throughout it. Teachers recognize efforts, work and challenges for interdisciplinary learning. However, there are still challenges to be overcome to effectively implement interdisciplinarity throughout the course. One of the teachers mentioned that he knows little about general education due to his tradition in students' professional training.

Regarding to organizing disciplines, the interpretation of teachers was diverse. Some of them adapted their courses to the ProFIS goals, others proposed contents totally different from those used in other courses at Unicamp. The methodology used was, for many teachers, different and more attractive.

The coordinator reported that he never saw teachers so dedicated, since institutionally, the workload only increased (joining the course is voluntary), with a major challenges of adapting their disciplines to the demands of the course. He felt that "everyone was proud".

Teachers pointed out that students changed their consciousness at the end of the course and many students pointed out that the main contribution of the ProFIS program was the interdisciplinary general education, which allows us to say that ProFIS has achieved its primary purpose. According to the evaluation made so far, we understand that, in the view of teachers, course coordinator and students, the two fundamental aspects of the ProFIS program are being gradually achieved.

\section{References}

Bach, L. (2010). Frontiers of Evaluation: Europe. Internacional Seminary Evaluation Frontier, Campinas, SP, 18-19 November 2010. http://www.ige.unicamp.br/fronteiras/palestras/18_930_LaurentBach.pdf

Bardin, L. (1991). Content Analysis. Lisbon: Edições, 70.

Aristotle (2005) Art Rhetoric and Poetics. (Trad. Carvalho, Antonio Pinto, 17th ed.). Rio de Janeiro: Ediouro.

Davis, J. R. (1995). Interdisciplinary Courses and Team Teaching: New Arrangement for Learning. Phonix, AZ: American Council on Education and Dryx Press.

Fazenda, I. (1999). Interdisciplinarity: History, Theory and Research (4th ed.). Campinas: Papirus.

Godoy, A. C. S. (2011). The University Teacher Professor as Trainer Human Capital Transformer. In A. M. G. Sperandio, \& R. Pantano Filho (Eds.), The Promotion of Life Construction: An Exercise in Interdisciplinary Approach (pp. 97-116). Indaiatuba: Vitória Ltda. 
Macdonald, B. (1982). A Political Classification of Evaluation Studies. In: M. A. A. Goldeberg, \& C. P. Souza (Eds.), Evaluation of Educational Programs; Vicissitudes, Controversies, Challenges (pp. 35-48). São Paulo: EPU.

Morin, E. (1999). Transdisciplinarity and Complexity: The Reform of University and Elementary School. Natal: Editora da EDUFRN.

Newton, R. R. (2000). Tensions and Models in General Education Planning. Journal of General Education, 49, $165-181$. http://dx.doi.org/10.1353/jge.2000.0023

Nussbaum, M. (1997). Cultivating Humanity: A Classical Defense of Reform in Liberal Education. Boston: Harvard University Press.

Pereira, E. M. A. (2002). Implications of Postmodernity for the University. Revista Avaliação, 7, 35-46.

Pereira, E. M. A. (2010). Curricular Reform at Harvard: The Centrality of General Education in the XXI Century. In E. M. A. Pereira (Ed.), University and Curriculum: Perspective of General Education (pp. 41-46). Campinas: Mercado de Letras.

Peterson, P. M. (2012). A Global Framework: Liberal Education in the Undergraduate Curriculum. In P. M. Petterson (Ed.), Confronting Challenges to the Liberal Arts Curriculum: Perspectives of Developing and Transitional Countries (pp. 1-23). New York and London: Routledge.

Repko, A. E. (2008). Interdisciplinary Research: Process and Theory. Thousand Oaks: Sage Publications, 416 p.

Zackiewicz, M. (2005). Trajectories and Challenges of Evaluation in Science, Technology and Innovation. PhD Thesis, Universidade Estadual de Campinas, Instituto de Geociências. 
Scientific Research Publishing (SCIRP) is one of the largest Open Access journal publishers. It is currently publishing more than 200 open access, online, peer-reviewed journals covering a wide range of academic disciplines. SCIRP serves the worldwide academic communities and contributes to the progress and application of science with its publication.

Other selected journals from SCIRP are listed as below. Submit your manuscript to us via either submit@scirp.org or Online Submission Portal.
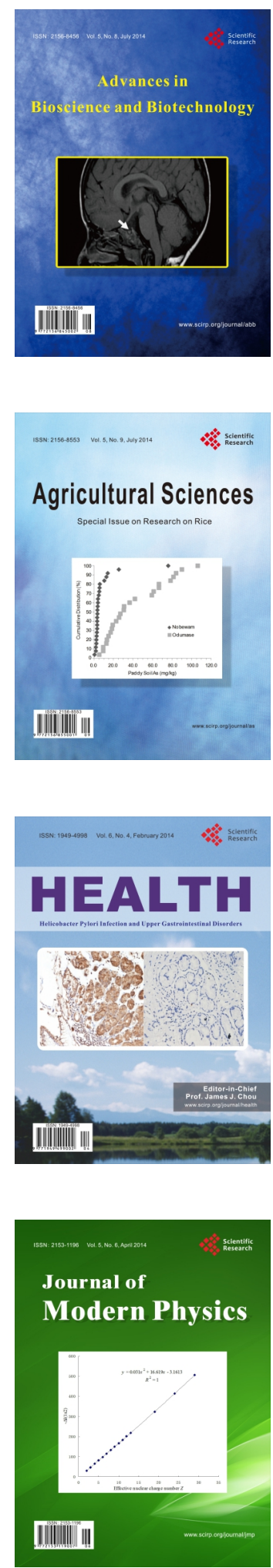
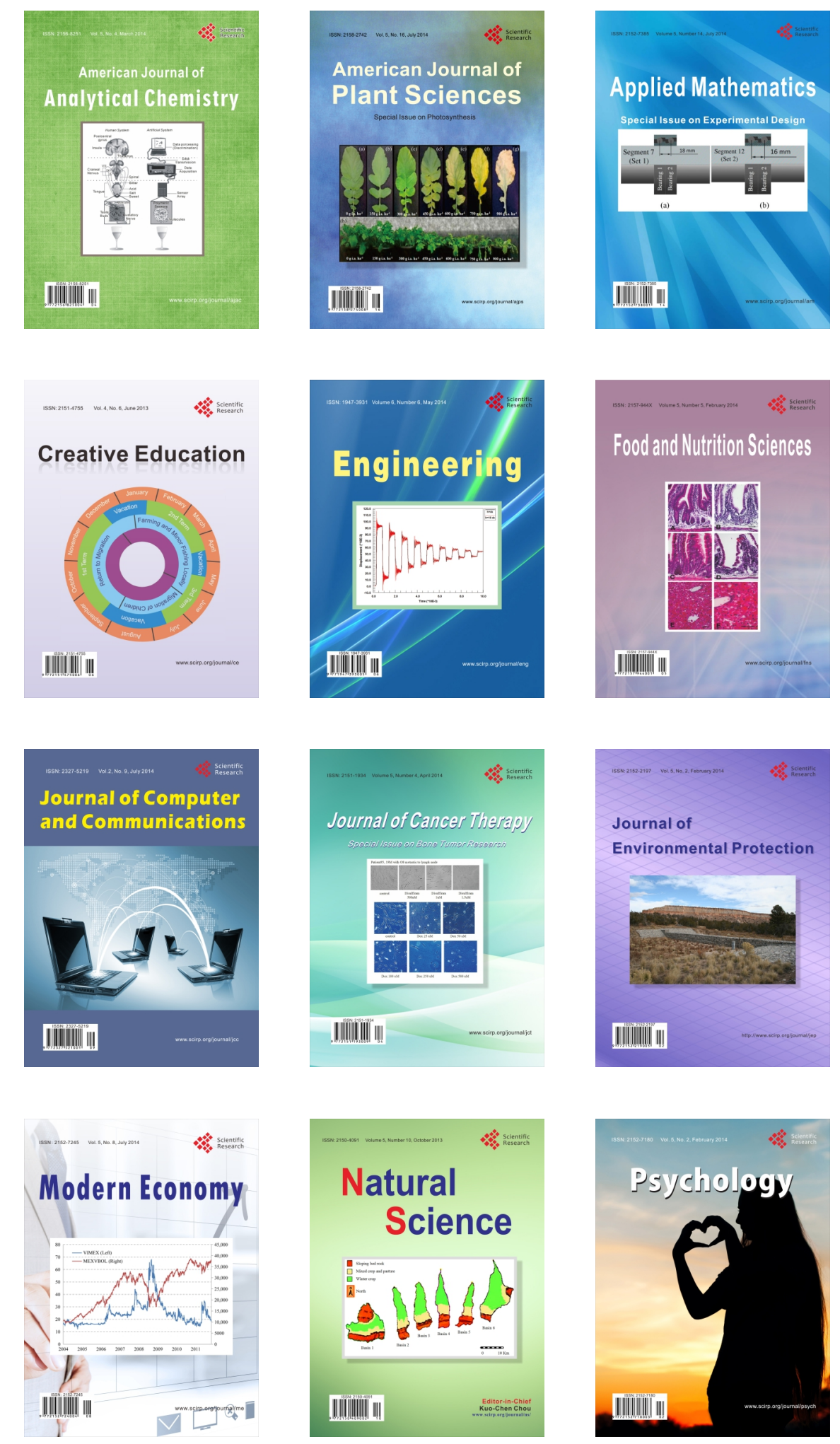